\title{
Cardiac Inflammatory Myofibroblastic Tumor
}

National Cancer Institute

\section{Source}

National Cancer Institute. Cardiac Inflammatory Myofibroblastic Tumor. NCI Thesaurus.

Code C45753.

An intermediate fibroblastic neoplasm arising from the heart. It is characterized by the presence of spindle-shaped fibroblasts and myofibroblasts, and a chronic inflammatory infiltrate composed of eosinophils, lymphocytes, and plasma cells. 